\title{
AL HILO DE LAS LECTURAS ESCOLARES Y LAS NUEVAS DEMANDAS EDUCATIVAS
}

Aitana Martos García

Universidad de Almería

RESUMEN: El artículo revisa desde un punto de vista crítico el estado del arte sobre las lecturas escolares, desde sus supuestos teóricos a su instrumentación didáctica y los puntos de vista de los profesores. A este respecto, son revisadas las aproximaciones de distintos paradigmas y autores, cuyas referencias y aportaciones son contrastadas con la encrucijada cultural actual y las percepciones de los alumnos y los docentes. La lectura y la escritura clásicas son desbordadas por conceptos como multialfabetización, transmedia, fan fiction, etc., y es la escuela la que debe facilitar modelos integradores y eclécticos de lecturas. También debe hacer converger los distintos medios y fomentar la participación (Jenkins), y todo ello sin perder como horizonte la literacidad crítica.

PALABRAS CLAVE: Lectura escolar, paradigmas, multialfabetización, literacidad crítica.

\section{ABOUT THE SCHOOL READINGS AND THE NEW EDUCATIONAL DEMANDS}

\begin{abstract}
This article reviews from a critical point of view the State of the art on the school readings, from their theoretical assumptions to their didactic instrumentation and the views of teachers... In this regard, are reviewed the approaches of different paradigms and authors, whose references and contributions are contrasted with the current cultural crossroads and the perceptions of students and teachers. Classical reading and writing are overwhelmed by concepts such as multialfabetizacion, transmedia, fan fiction, etc, and the school is which should facilitate models integrators and eclectic readings. Also make converge the media and encourage the participation (Jenkins), and all of this without losing the critical literacy as a backdrop.
\end{abstract}

KEYWORD: Reading teaching, paradigms, multiliteracies, critical literacy.

Recibido: 26/04/2016

Aceptado: 04/11/2016 
Correspondencia: Aitana Martos García, Facultad de Educación de la Universidad de Almería, Departamento de Educación, Área de Didáctica de la Lengua y la Literatura, Edificio Científico Técnico III (CITE III), 04120 Almería. Email: amartosg@ual.es.

\section{INTRODUCCIÓN}

La sociedad de la información está generando fenómenos nuevos, pues el procesamiento masivo de datos brinda nuevas posibilidades en el ámbito de la lectura, de modo que tal abundancia de referencias lo que promueve es una cultura más descentralizada, colaborativa y que favorece la publicación en abierto en consonancia con el movimiento open-source.

Los cambios culturales y tecnológicos son tan acusados que la "lectura contemporánea" (Cassany, 2006) ya no se puede entender a la luz de los parámetros tradicionales ni de la cultura letrada clásica (Chartier, 1992). Todo lo que Cucuzza (2011) ha descrito como "escenas de lectura", en el marco de los estudios del Proyecto Histelea, supone una andadura compleja, "desde los catecismos coloniales a las networks estatales".

Centrándonos en la selección de textos y en la orientación de la tarea escolar, podemos subrayar algunos principios que han regido en Europa en los catones y libros de lectura. Así, en la tradición escolar francesa del s. XIX y gran parte del XX, instrumentos como la explicación de textos, la lectura intensiva o el comentario de textos eran métodos hegemónicos, muy extendidos (Butlen, 2005). De tal modo que leer se equiparaba a hacer esta lectura comentada, en realidad una forma de paráfrasis que buscaba la lectura comprensiva a través de diversas preguntas, actividades de vocabulario, etc. y donde el profesor era el "solucionario". A lo sumo, este tipo de material estaba concebido como una especie de aparato crítico con suficiente información literaria, histórica y retórica para que los alumnos retuviesen esas informaciones y, como mucho, repitiesen una y otra vez las tareas prescritas en el manual (Dufays, 2005, p. 25).

A esta práctica social de la lectura, aparte de sus condicionantes materiales o tecnológicos, subyacía, en cuanto a la textualidad, la preconcepción de que existía un corpus jerarquizado de textos, un círculo restringido de lectores y un modus operandi que asimila el papel del profesor al del cura (Butlen, 2005), puesto que se trataba de "profundizar" y esclarecer el sentido mediante unas determinadas pautas, como el de orientar o "sesgar" -si hablamos de "lecturas patrióticas" - la interpretación admisible del texto. En cambio, las prácticas educativas más modernas insisten en técnicas conocidas como el skimming o el scanning (Muter y Maurutto, 1991), y se orientan hoy más bien a hacer "barridos" del texto y/o localizar una información muy específica, es decir, tienen una orientación estratégica del que carecían aquel tipo de tareas.

Un elemento esencial ha sido la familiarización de ciudadanos con Internet, esto es, la lectura hipertextual por ejemplo, que ha modificado la lectura lineal y ha hecho emerger otras percepciones de la lectura como navegar e incluso como "surfear" (Fainholc, 2004). En este contexto, "leer la ola" no es extraer un significado profundo sino saber elegir en función de una visión previa estratégica, esto es, 
primando la lectura aferente sobre la eferente. De hecho, las investigaciones sobre las diferencias entre la lectura en pantalla y la lectura en papel (Muter y Maurutto, 1991) vienen a subrayar que la lectura en el computador puede ser más eficaz debido a la cantidad de información mientras que la lectura en papel es más eficiente, ponderando la diferencia que hay entre el interface del ordenador y su percepción como texto o "rollo" continuo, frente a la percepción del formato "códice" que predominan en la cultura escrita, que ayuda a formarse una representación global del texto.

Es éste un ejemplo revelador de cómo, siguiendo a Chartier (2006) la textualidad del libro y la materialidad del texto se interpenetran. La "escena de lectura" y la materialidad del texto preorienta de algún modo el sentido, del mismo modo que los géneros y singularidades de los textos también están generando cambios notables en los soportes y marcos actuales de la lectura. Por ejemplo, la narrativa de los Ilamados "textos continuos" -como las sagas- ya no se presta ni al formato "códice" ni puede presentarse como en las escenas de lectura donde se leían en voz alta fragmentos de obras conocidas.

Como pasa con las series de éxito en televisión, los nuevos lectores tienen que desarrollar habilidades nuevas y contextos nuevos, por ejemplo internet, los dispositivos móviles o las APP, para acceder a los textos de otra manera, por no hablar de los textos multimodales. Lo cierto es que la sociedad de la información -por ejemplo una simple búsqueda de libros en una web como Amazon- presupone una serie de mecanismos como la lematización y otros, que conoce bien un lingüística o un documentalista pero que el usuario profano solo vislumbra en forma de etiquetas o descriptores, sin saber que las recomendaciones de otros libros similares están generados por sistemas robotizados.

En esta perspectiva la literatura es vista desde métodos cuantitativos (Moretti, 2007) o bien desde un enfoque de macroanálisis (Jockers, 2013) y cobra un sentido difernete, variando no solo el paradigma de estudio sino el objeto mismo de la investigación, que apenas es ya la singularidad de un determinado texto o autor -por importantes que sean o lo reconocidos que estén dentro de un canon- sino todo lo contrario: un "flujo" de textos (en forma de colecciones, registros o corpus de publicaciones) de los cuales se pretenden extraer patterns, es decir, patrones que lleguen a ser significativos. El cambio de escala, el estudio masivo de datos que va a propiciar el análisis computacional aplicado a distintos soportes digitales (bases de datos, textos) es lo que hace que estos métodos computacionales sean, no ya un auxiliar de la investigación, sino el foco mismo de la misma.

Por citar un ejemplo emblemático, las antiguas "Concordancias" en corpus textuales eran ya un método reconocido para contrastar todas las variables dentro de un autor o género preseleccionado. Así, conocemos las concordancia sobre clásicos, como Santa Teresa de Jesús (De San José, 1945). Sin embargo, el alcance o escala macroscópica de los textos no es tan fácil de perfilar, en la medida en que los textos no se comportan exactamente como puntos discontinuos en una representación en google maps, a modo de nodos cuyas conexiones podamos entrelazar. Para empezar, no son a menudo entes describibles de forma "sólida" (un poema, un libro...) sino son en realidad como flujos, fragmentos o partes de un continuum que se pueden 
agrupar de diferentes maneras: como textos sueltos o bien "arracimados" en antologías o compilaciones, que según un proceder que cada época y según la recepción de dicho texto se articula de distinta manera.

Por otro lado, al análisis cuantitativo se le pueden pasar por alto importantes mecanismos, como es precisamente "lo que no se dice", bien por factores de censura o tabú, bien porque se omita, se diga en perífrasis o circunloquios, o por otra causa. El nombre de las figuras populares que dan miedo (monstruos, diablos, asustaniños...) es un ejemplo ilustrativo del enorme peso de factores culturales sobre la lengua y la literatura. Cualquier macroanálisis de nociones como "virgen", "encantada", "diablo" en un corpus dado, como el de leyendas iberoamericanas, requeriría de una desconstrucción y una contextualización, esto es, de un glosario a partir de criterios cualitativos.

Cierto que estos nuevos enfoques han permitido una aproximación menos textocéntrica, en el sentido de que ya no es suficiente con el aparato crítico que acompañaba la lectura intensiva de los clásicos, con información literaria, histórica, retórica, etc. En realidad, lo único que se pedía a los estudiantes era que retuviesen estas informaciones y, a lo sumo, que emulasen estos procedimientos de análisis ya preestablecidos del texto (Dufays, 2005: 25), como la explicación o el comentario de textos. La minería de textos o el análisis de contenidos en realidad ponen en relación nociones relevantes, como es el tópico de la honra en la literatura clásica española, con muchos otros conceptos, y en esa medida tiene un potencial heurístico que los métodos computacionales ayudan a descubrir.

En pocas palabras, estamos ante un paradigma nuevo que dos autores han sabido caracterizar acertadamente. Por un lado, Jenkins (2006) ha descrito como la cultura de la convergencia de los medios y la participación: así es, los nuevos discursos transmedia están suponiendo un acercamiento y una proliferación de textos híbridos y multimodales, que recuerdan en suma a la novela gráfica y otras producciones contemporáneas. Por otro lado, Bauman (2002) ha acuñado el concepto de modernidad líquida para subrayar que estos textos "líquidos" ya no se pueden manejar del modo que el libro "sólido" y perfectamente acotado. Y que esto afecta no solo a las formas sino también a los contenidos, sujetos a una incesante "erosión", desgaste o relativización.

Las historias ya no tienen la vía preferente de la oralidad o de la cultura escrita impresa: las historias se ramifican en un universo transmedia, con ficciones no solo en libro sino en cine, cómic u otros medios, que son indexadas con tópicos y descriptores similares. Véase a este respecto el ejemplo de Tropes TV, http://tvtropes. org/ (Martos et al., 2014), una wiki en inglés que constituye una suerte enciclopedia multimediática de ficciones que recoge registros en campos como literatura, cómics, videojuegos e incluso publicidad televisiva y deportes. Es realmente una macrobase de datos donde a partir de elementos tematológicos predefinidos de ficciones muy diferentes se enlistan una serie de apariciones o recurrencias en los distintos lenguajes.

Sería, pues, un buen ejemplo, a su manera, del procesamiento de datos a escala macroscópica -es decir, masivo de datos- que se postula, y por eso Moretti (2013) ha acuñado el concepto de distant reading. Esta posición supone invertir el foco respecto a la escuela tradicional, porque en el fondo ya no estamos simplemente ante expresiones singulares de textos, ya sean convencionales o multimodales, sino, cada vez más, ante bases de datos (Lovink, 2013). 
En cuanto a la cultura de la participación que subrayaba Jenkins (2006), no olvidemos que prácticas como el fan fiction y en general los fans agrupados en comunidades está suponiendo un nuevo tipo de público y una nueva actitud ante la lectura y la escritura, que está en las antípodas de la lectura escolar, aunque se ha generado como un movimiento de imitación de textos que han alcanzado éxito, por algún motivo, desde clásicos a sagas contemporáneas. Ya pasó con el Quijote, la literatura está llena del efecto de las imitaciones y modas, pero también vive del afán de innovación y ruptura respecto a convenciones y temas dominantes

\section{LA LECTURA ESCOLAR EN SU LABERINTO}

Ciertamente, la lectura escolar tradicional y las nuevas formas de lectura entran en colisión no tanto en los textos como en los usos. El artefacto textual (Iser, 1987) es siempre un potencial de sentido que se actualiza en el acto de lectura, que se puede contextualizar o descontextualizar según los condicionantes. La "perennidad" de los clásicos estaría, según Calvino (2012), no en que sus textos se presenten en un formato u otro, sino en su capacidad de generar una respuesta "dialógica" en el receptor, si bien esta capacidad de provocar interrogantes solo se activa gracias al trabajo de un educador o "mediador" de lectura.

El análisis de Butlen (2005) pone el dedo en la llaga sobre paradoja y contradicciones de la lectura en el ámbito escolar. Es importante subrayar el ámbito escolar como un espacio sui generis, porque el terreno educativo es sin duda un ecosistema singular, diferente al bibliotecario o al mundo del mercado donde se comercia con libros. Un alumno no es lo mismo que un cliente de una librería o un usuario de una biblioteca pública: es un "formando", y eso también lo diferencia de un ciudadano a secas, es un "lector en construcción" sobre el cual el profesor no puede declinar sus responsabilidades, algo que sí puede hacer el vendedor de libros o el archivador. Dicho de otro modo, la lectura escolar es lo contrario a la omisión, es siempre una apuesta de intervención, en una dirección u otra.

La lectura escolar orbita, pues, en torno a conceptos específicos como el del canon escolar, el del currículum, la educación literaria, la pedagogía de la lectura, etc. Todo ello hace que la aproximación psicopedagógica haya primado conceptos como el de competencias lectoras y, por tanto, la dimensión del desempeño, y también las variables individuales en la adquisición y perfeccionamiento de la lectura y la escritura.

Sin embargo, las nuevas condiciones culturales han modificado sustancialmente esta perspectiva digamos "aislacionista" de la escuela, respecto a las metodologías de dinamización de la lectura. La eclosión de la información y el perfil de los nuevos lectores como prosumidores mediáticos han cambiado de raíz el modelo logocéntrico/textocéntrico de la educación lectora clásica. De hecho, es el modelo de la cibercultura el que ahora impregna todo: igual que hablamos de nativos digitales (Prensky, 2011), o de la cultura de la convergencia y la participación (Jenkins, 2006), hoy ya se habla dentro de la Didáctica de la Lengua y la Literatura de "escrilectores" (Rodríguez, 2005) o de competencias digitales como parte esencial de las competencias comunicativas. 
Esta "apertura de campo" va por tanto en una doble dirección: "continentes" y "contenidos". La primera es la más visible porque el "reinado" indiscutible del artefacto "libro impreso" -como término cuasi equivalente a "cultura escrita" - ha dado paso a una fragmentación y multiplicación de soportes, dispositivos y canales, desde la tableta a los transmedia. De hecho, ocurre que los propios universitarios que se están formando para ser profesores, lo que usan en sus trabajos académicos es sobre todo Internet, más que la bibliografía clásica.

A saber, links de Internet, Wikipedia, Redes Sociales, etc., convirtiendo estos medios en la fuente primaria de información, frente a la concepción casi artesanal de la consulta de información como algo que se hacía de forma manual, en una biblioteca o, en todo caso, hojeando libros.

Recordemos que Butlen (2005) razonaba que el fin último de la lectura escolar debería ser el acceso a la lectura "privada". Obviamente, dentro de la mentalidad de la "cultura letrada", lectura privada equivale a la lectura individual, personalizada. Pero los historiadores de la cultura han documentado con precisión "prácticas de lectura y devoción en soledad" (Morant, 2009:21), valores vinculados a la emergencia de conceptos de privacidad o de intimidad frutos de la evolución social de Europa burguesía. Tales usos elitistas se prodigaban en "pequeñas sociedades", como los salones, academias y tertulias. La paradoja está en que la herencia de estas prácticas supuso una contribución a la democratización (por ejemplo, el modelo de la República de las Letras), mientras que en el modelo actual de la sociedad global, del "aula sin muros" los que imperan son Star Wars y otros imaginarios muchos menos proclives a los librepensadores, sea cual sea el número avasallador de sus públicos.

En cualquier caso, la emergencia de lo privado y de lo íntimo en el mundo de las prácticas de lectura se va a traducir en formas de devoción, arquitecturas domésticas, estilos de vida familiar y de sociabilidad, literatura y prácticas de civilidad o formas concretas como la literatura autógrafa (Chartier, 1992). Este mismo concepto de "interioridad" relacionado con la conquista de la intimidad individual se va a reflejar en tópicos como el gusto por la soledad, lo cual está en las antípodas del sentido actual de lo comunitario, tan diferente. Por citar un caso emblemático, el público femenino burgués, ilustrado y culto, es el que disponía de tiempo y espacios privados para la lectura de géneros como los folletines sentimentales o las primeras revistas de moda.

En cambio, las teorías del "paréntesis" de Gutenberg (Sauerberg, 2009) subrayan que en realidad este auge de la cultura escrita clásica (Chartier, 1992) ocuparía un breve período cultural, en términos relativos, flanqueado por dos grandes lapsus de tiempo donde la oralidad sería la práctica dominante. En nuestro días de "pantallas ubicuas" (Piscitelli, 2011), hablamos de una oralidad secundaria o mediada (Ong, 1993), pero lo cierto es que la lectura burguesa -reposada, reflexiva o adscrita a ciertos espacios y tiempos de privacidad- es algo obsoleto o en claro retroceso.

Así, cuando se habla ya de hyper-readers que "sobrevuelan" un (hiper)texto, en realidad lo que se evidencia es una práctica propia de la cibercultura y de la posmodernidad. El problema es, además, que hay miles de textos que es imposible de leer al modo clásico (Moretti, 2007) y, por tanto, el manejo de la información ya no puede ser el mismo que el específico de la lectura clásica a la que aludía Butlen; ya no cabe acudir a un modelo clásico basado en una estratificación, en una jerarquía 
entre textos superimportantes - donde se centraba la explicación de textos- y textos desdeñables o poco valiosos. Hoy leer un texto en el mundo de la información "masiva" es saber etiquetarlo, por lo cual apenas cabe hablar de un texto singular, ni la experiencia enriquecedora para un individuo peculiar y mucho menos del debate intelectual como prioridad de la lectura, al modo del modelo de la citada República de las Letras (Martos, 2012).

En contra de este "vaciamiento" de la lectura clásica para convertirla en una especie de taxonomía o nube de etiquetas han surgido voces que reivindican la "literacidad crítica" (Cassany, 2006) o la necesidad de un pensamiento disidente (Sánchez Corral, 2005), que a fin de cuentas no es más que volver a un planteamiento sociocrítico. Especial valor tienen en este sentido los NEL (Nuevos Estadios de Literacidad) y sus auspiciadores (Barton y Hamilton, 1998). No es que sea ninguna novedad la sociología de la lectura, pero a diferencia del enfoque economicista de Escarpit (1958), no se trata solo de examinar los canales de producción o distribución de las publicaciones, sino de entender que en su raíz el acto de leer es un hecho social propio de la "mente letrada" (Olson, 1994), y por tanto esta autoconciencia personal está ligada a una "emancipación" también del grupo, esto es, a una creciente percepción de autonomía y de empoderamiento de los grupos sociales, subyacentes a la idea de "librepensador" "como avanzadilla" de los sectores sociales que buscan reformas.

\section{NeCesidad de una lectura crítica. Omnivorismo cultural y Cultura POSTIPOGRÁFICA}

De modo que defender esta dimensión humanista y crítica de la lectura no debería circunscribirse a testimoniar una cierta forma de lectura vinculada a las élites o clases dominantes de la Europa moderna. Más bien, las nuevas perspectivas ponen en valor la lectura como empoderamiento y como una forma activa de "pegamento social", y reivindican expresiones populares antiguas (las denominadas "escrituras populares" de las clases subalternas) o bien modernas (la cultura popular actual, por ejemplo, el mundo de los fans, el fan-fiction, etc.).

Todos estos nuevos posicionamientos no solo vienen impulsados por cuestionamientos políticos o revoluciones sociales. La propia praxis social está cambiando de facto todos los esquemas. Por eso, en la Ilamada cultura postipográfica surgida al amparo de la revolución digital (Giesecke y García, 2009), tan abiertas en las formas y en los soportes, sigue siendo necesaria la lectura crítica que emerge de los modos modernos de la sociabilidad burguesa.

Precisamente, el concepto de omnivorismo cultural (Peterson, 1992) se acuña cuando se detectan que los nuevos consumos quiebran la imagen preconcebida de las clases elitistas, que ahora ya amplían sus prácticas y estilos de vida en contraposición al mundo descrito por los historiadores del s. XIX.

Fruto sin duda de este ambiente de posmodernidad y de "bricolaje" cultural, lo que prima ahora es un sentido de la hibridación, que lleva a la customización o personalización de mitos y lecturas ("tuneo", en la expresión de Martos, 2006). Solo así es entendible el éxito de obras como Star War o Juegos del Hambre, síntomas de utopías o distopías que cada comunidad se apropia a su modo. La koiné de lecturas que 
subyace a este cultura popular moderna es un signo claro del canon de lecturas que actúa como el currículum oculto o paralelo, respecto al canon escolar "bien intencionado" que es objeto de recomendación por los agentes educativos. Es muy difícil que la lectura escolar clásica compita con este despliegue multisensorial que supone cada una de estas obras, que se convierten en objetos de culto para muchos jóvenes, esto es, en una suerte de lecturas adictivas.

Al hilo de esta misma analogía dietética, igual que hace falta una educación del consumidor en forma de dietas frente al valor "tóxico" de ciertos inputs, algo similar cabría decir en el terreno de la lectura. Necesitamos nutricionistas de la lectura que hagan planes individualizados de lectura, y con ello volvemos a las ideas de Butlen (2005), porque tales nutricionistas no serían otros que los profesores y, en general, los mediadores de lectura. Un desarrollo equilibrado obliga a estudiar los sujetos educativos, pero en sus entornos e interacciones. Una dieta se lleva a cabo mejor si es compartida, no en vano las tertulias dialógicas o el apadrinamiento lector serías líneas en esta dirección.

En un contexto pues de sociedad abierta (Popper, 1992) y de aprendizaje "liberal" (en el sentido de Oakeshott, 2009), aprender a leer sería un entrenamiento en el ejercicio de la ciudadanía y de la libertad. También de la innovación, como sostén de las sociedades abiertas.

La preconcepción de que una lectura escolar es igual a una lectura de textosy/o autores tiene graves implicaciones de cara al currículum, pues se concibe que un canon de lecturas es una lista de autores y/o textos. Si se centra en autores se incurre a la fuerza en una historiografía de la literatura clásica, esto es, en una jerarquía elaborada a partir de las historias de la literatura, cuyos vaivenes conocemos. De hecho, la deriva en este sentido de las literaturas nacionales o en determinadas lenguas hacia otras formas de parcelar introducen más elementos de confusión. Bajo el membrete de "escritores andaluces" se podría elaborar una lista basada solo en este criterio, que es anecdótico al fin y al cabo.

Si el criterio elegido es por textos nos encontramos con otros problemas no menos complejos. Los textos "sólidos", por usar una terminología de Bauman (2002), es decir, los libros reconocidos como tales con un texto canónico establecido, no pueden ocultar que hay muchos otros textos "líquidos", por ejemplo, la literatura de base tradicional, cuentos, romances, canciones, obras de teatro popular, etc. que circulan en variantes. Pero es que, además, en Internet tampoco los textos de la cibercultura son estables, sino que se prestan a todo tipo de modificaciones, "amputaciones", etc.

Tampoco la literatura culta puede evitar este problema de la integración de textos, como ocurre con las antologías líricas colectivas o las antologías de cuentos. La integración de textos es, pues, una forma de (sobre)interpretación de textos. Los manuales o antologías de lecturas escolares han creado esta forma de "ensartar las cuentas" de este imaginario collar de lecturas, a base de isotopías religiosas, patrióticas, etc., que al final reproducen el modelo de las lecturas de civilidad de la sociedad burguesa, esto es, lecturas "correctas" según la mentalidad imperante y el modo de recepción de los textos en cada etapa cultural. El Quijote es un buen ejemplo de todo estos azares, pues ha pasado por todo tipo de (re)lecturas, desde las de más rancio abolengo, como símbolos de la raza hispánica, a las más contraculturales, en defensa 
de la locura como forma de de-construir la sociedad (Martín-Santos, 1975). El debate sobre si debía imponerse la lectura del Quijote y sus posibles abusos en su traslación al aula (Ortiz, 2005) no es más que la expresión de las propias contradicciones de la lectura escolar, de sus impotencias al convertir en una suma de estereotipos una obra tan bajtiniana de raíz (Bajtin, 1974).

En este contexto, el paradigma de la mercantilización de la cultura imperante en nuestra sociedad, que crea ingentes industrias del ocio ("capitalismo de ficción", Verdú, 2006) es como Jano, tiene una doble cara. La positiva es la producción incesante de Imaginarios, de ficciones y creaciones de toda índole que inundan el mercado de cifras "apabullantes", como las de la entrega de la última parte de la Saga Star War, que hacen palidecer cualquier éxito editorial pasado -como el de El Quijote- o presente. Además, la producción de ficciones ya no está generada desde compartimentos estancos, no hay en sentido estricto novelas, filmes o animaciones como productos separados que ocasionalmente se "interpenetran". La "porosidad" (Besson, 2004) de las sagas y series modernas es tal que en la narrativa transmedia lo que se programa es un conjunto transficcional, esto es, una especie de discurso pansemiótico, donde la "historia profunda" puede encarnarse en muy diversos moldes o avatares.

\section{EL MODELO DE EMPRENDIMIENTO Y LA MODERNIDAD DE LOS CLÁSICOS}

Hablábamos de Jano. La cultura del emprendimiento también se ha orientado a actuaciones altruistas, como la del emprendimiento social. $\mathrm{O}$ ha puesto en valor conceptos económicos pero de gran importancia para la lectura. Por ejemplo, fidelizar las lecturas, porque el problema a menudo no es hacer lectores sino mantenerlos.

Otro ejemplo es el ya citado de la customización de mitos y lecturas. En los librosregalo el mercado ofrece ejemplos toscos de personalizar una historia, a partir de un patrón. Las series y sagas de éxito, como Percey Jackson, ofrecen modelos algo más complejos. Importan o se apropian de tradiciones de todo tipo, resignificando así tanto aspectos tangibles como intangibles de su entorno, a menudo impulsados por una demanda creciente de los fans, el turismo, etc. Es el caso del Empire State Building y King Kong, también en la saga Percy Jackson de R. Riordan, el Olimpo es accesible a través de un ascensor de Nueva York.

Customización es, pues, sinónimo de apropiación (Martos, 2011), noción chartreana que vuelve a poner el énfasis en las capacidades de recepción de los lectores y en su entorno también. El concepto de clásico (Calvino, 2012) debe ser repensado y resituado a la luz de estos nuevos paradigmas tanto literarios como didácticos, y conceptualizado igualmente desde una perspectiva histórico-literaria. Esta reflexión sobre los clásicos y su implementación didáctica nos permitirá una reformulación del alcance y sentido de la lectura literaria, y de cómo ésta debe ser instrumentada teniendo en cuenta la propia historiografía cultural y su conexión con el mundo educativo y cultural, así como las demandas de la nueva sociedad del s. XXI.

Se hace necesaria una nueva síntesis que busque de forma ecléctica una actualización crítica de los contenidos y una renovación de las metodologías. En particular, y a través del concepto de adaptación, debemos reapropiarnos de los textos clásicos con nuestros gustos actuales, indagando textos que nos sigan proponiendo 
interrogantes, y que podamos "tunear" o "customizar"; a su vez, sería útil rastrear elementos de los clásicos presentes en obras artísticas de diversa índole, con las que se establezcan conexiones de todo tipo susceptibles de ser incorporadas a propuestas didácticas concretas.

\section{CONCLUSIONES: NECESIDAD DE UNA LECTURA (RE)INTEGRADORA}

Esta variabilidad o labilidad de formas (lectura multimodal) tiene también su repercusión en los contenidos, no es "inocua". Ficcionarios como Tropes TV es un ejemplo de este "enmarañamiento", en el que una misma etiqueta puede en realidad referirse a cosas radicalmente distintas o incluso contrapuestas, desde una versión naïf hasta ciertas escrituras pornográficas. Los mitos, cuentos y leyendas son en especial palimpsestos muy susceptibles de estas "transmutaciones" lo que nos Ileva nuevamente a la necesidad de literacidad crítica (Cassany, 2006), de "depurar" estos efectos a veces perversos de los productos dominantes en un mercado. Esto es especialmente importante si tenemos en cuenta que los niños son lectores vulnerables, en construcción (Castedo, 1995), fácilmente sensibles a las "lecturas tóxicas" o adictivas.

Butlen (2005) ponía el dedo en la llaga en varios puntos clave para la cuestión que nos ocupa:

a. El desinterés hacia la lectura (crisis de la práctica de la lectura; paradoja: hay más libros e información que nunca).

b. Modelos escolares caducos, como la lectura intensiva a partir de clásicos como lecturas obligatorias.

c. La conclusión de que la lectura escolar en el fondo no tiene otro sentido que llevar a la lectura privada o personal, a la lectura como apropiación.

d. Lectura como apropiación (Chartier, 2006), el lector la hace suya, la interioriza, la reflexiona dialoga con ella (Bajtin, 1974).

e. Las lecturas no son solo apropiadas o inapropiadas por la edad, los temas o el lenguaje: debe ser apropiadas en este sentido de Chartier, deben ser significativas para el destinatario, y tratar de grandes interrogantes, que según Chartier es lo que caracteriza a los clásicos. Por ejemplo, Frankenstein de Shelley se anticipó a los problemas actuales de la genética, la robótica, etc. en el sentido de plantear si se puede (re)crear una persona, si con implantes, etc. se puede, como un cyborg, crear un ser humano, y qué implicaciones tiene eso para los sentimientos (el monstruo dice actuar así por la soledad).

Ciertamente, la lectura escolar, diacrónicamente, ha orbitado en torno a modelos y prioridades muy diferentes. Un ejemplo de ello son las controversias clásicas ha sido el didactismo excesivo de las lecturas pedagógicas o, dicho de otro modo, la instrumentalización de los textos para "inocular" valores tales como la urbanidad, la ideología de un régimen totalitario, los estereotipos sociales más admitidos, etc. Los defensores de la lectura estética abominan de este tipo de lecturas tan "explícitas" y defienden que los valores de una lectura es mejor que se "infieran" (Sánchez Corral, 2005), incluso cuando se cuenta un cuento. Desde luego, las moralejas de Perrault 
son "postizas", a menudo poco afortunadas, sobre historias tradicionales, porque simplifican o "cierran" sus significados, dándoles sesgos que podan las capacidades hermenéuticas del lector.

Otros puntos controvertidos se refieren a dónde ponemos el foco: en un tipo de escuela como la francesa lo esencial eran los textos, y de hecho durante un tiempo los comentarios de texto lo inundan todo. Tampoco podemos poner el foco o énfasis solamente sobre los medios impresos o el canal (libro), si no queremos incurrir en textocentrismos, es decir, en una atención excesiva y excluyente hacia la cultura escrita.

Acaso la forma equivalente a este tipo de lector culto que accedía a una cultura letrada en los s. XVIII y XIX (dentro de la sociabilidad burguesa) sea ahora la de un lector polivalente, que sepa moverse en una cultura postipográfica -por ejemplo, sabe seguir un relato en una narrativa transmediática- y que se adapte a las nuevas formas de sociabilidad, como las redes sociales. Con los medios audiovisuales, las NTIC, Internet, etc. volvemos en cierto modo a las características de la era pre-imprenta: se le vuelve a dar importancia a lo oral, los textos y discursos se reelaboran, todo vuelve a ser colectivo de alguna manera: es la cultura de la apropiación, el sampleo o el remix, variantes que se refieren a las mezclas que se hacen por ejemplo en el hip hop y otros estilos musicales. Sea como sea, todo esto no sería un retroceso sino una recontextualización.

Esto iría en consonancia con la teoría de la Oralidad Secundaria (Ong, 1993). Subrayaba que, mientras que antes de la imprenta existía una "oralidad primaria" donde comunidades cerradas se transmitían el conocimiento de forma oral y comunitaria, ahora en Internet impera lo que se Ilama "oralidad secundaria": una comunicación basada en la escritura pero que absorbe rasgos de la comunicación oral que facilitan las NTIC. Así, se (con)forman comunidades donde se tiene la sensación de pertenencia, de empatía o subjetividad -como en los foros, chats o blogs- y todo ello crea un nuevo sentido de privacidad.

Ciertamente, en esta cultura post-paréntesis (Sauerberg, 2009), donde se reafirma la oralidad y sus nuevas formas (Ong, 1993) por encima de la cultura escrita clásica, muchas producciones son remezclados, versionados o mash-ups (es decir, hibridaciones) de cosas existentes anteriormente, lo cual nos devuelve a esa lucha que he comentado entre libertad del arte, de la creatividad vs. el derecho de autor, lo cual es un imperativo legal pero que cultural y antropológicamente no tiene mucho sentido porque todo el arte deriva de otro anterior.

Otra forma de lucha por la creatividad es la cultura jamming, que consiste simplemente en todas las manifestaciones de rebeldía, de resistencia contra la cultura popular "aceptada". Se dedica a transformar los mass media existentes a fin de generar un golpe negativo sobre ellos mismos, usando el mismo método de comunicación. Utilizan un medio, un arte, una obra y la desvirtúan para satirizar o criticar. Pero eso, a fin de cuentas, es lo mismo que la parodia bajtiniana ya presente en el carnaval medieval.

Volviendo al paréntesis de Gutenberg, Hervé Fischer (2002) decía, en cambio, que no habría tal paréntesis en forma de ruptura entre una cultura y otra, sino una fluctuación. Ejemplo: el ebook no rompe con el libro tradicional, sino que es una evolución, una continuación, una remediación (Bolter et al., 2000) en suma. 
En definitiva, coexisten viejas y nuevas prácticas de lectura, y a ello se agregan formas nuevas de expresión de la creatividad y la comunicación, sobre todo al amparo de las NTIC e Internet. No hay que olvidarse de lo esencial: el pensamiento crítico, la capacidad de discernir, de adquirir/enseñare criterios, claves, pistas... Por tanto, la hibridación propia de nuestra época debe guiarse por una "gobernanza" del saber que visualice no solo "pantallas ubicuas" (Muter et al., 1982) sino también formas y prácticas de lecturas ubicuas, desde la oralidad a la cultura escritura clásica, desde el manuscrito a la tablet, desde la literatura autógrafa -como el diario íntimo- al gran ágora de la cibercultura.

La lectura escolar sigue siendo, por consiguiente, la llave de lo que indicaba Butlen, el acceso a una lectura personal, y, por tanto, a una lectura como diálogo, polifonía o disidencia, que debería armonizarse con las concepciones más funcionalitas o pragmáticas. Precisamente los textos, por su elasticidad-recordemos la noción de Iser (1987) del artefacto textual como un potencial de sentido- dan sentido a todas estas formas de "manejo" y reutilización, pues los buenos textos son como auténticos manantiales, cuanto más agua brota más se llena el pozo. Y todo ello como antídoto frente al adoctrinamiento, la exclusión o el vaciamiento de las lecturas en el ámbito de la escuela.

En un entorno de creciente "modernidad líquida", el reto educativo es re-significar estas lecturas escolares, y para ello hay criterios académicos, didácticos y culturales suficientes. Es decir, hay toda una elaboración académica en torno, por ejemplo, a la literatura infantil y juvenil, que pueden servir de "metalecturas" capaces de orientar al docente.

Del mismo modo, hay un mínimo consenso en la defensa de valores humanos universales, con los cuales el docente puede comprometerse a "armar" los itinerarios de lectura para sus alumnos. La democratización, el rechazo a la violencia, la defensa de los derechos humanos, la conservación del medio ambiente, entre otros, son temas capaces de generar ese consenso tan necesario, más allá de las "nodas pedagógicas" y de las distintas instrumentalizaciones didácticas.

Una nueva praxis educativa debe estar dirigida a convertir a los alumnos en ciudadanos polialfabetizados (Piscitelli, 2011), pues la lectoescritura clásica es desbordada por fenómenos como los transmedia. El denominado digital storytelling significa que las viejas historias -incluidos los clásicos- son ahora "re-contadas" con ayuda de plataformas, lenguajes y canales de gran riqueza y variedad, desde el lenguaje pictórico y musical a los videojuegos, y que todo eso impacta sin duda en el mundo familiar y escolar.

Tales elementos emergentes ya no son simples auxiliares didácticos sino la forma misma en que las historias van "migrando" y adaptándose a los nuevos contextos de producción y recepción, y se van pudiendo contar en formatos cada vez más diversificados: libros, CD, periodismo, TV, Radio, Movies, DVD, Webisodes, Podcasts, Twitter, Facebook, YouTube, Pinterest, Instagram, Smart phone apps, Tablet apps, Cómic, novelas gráficas, Video games, Flash mobs, documentales, Quizzes, Board games, Fan fiction...

En suma, asistimos a una maraña de medios, pero también a una encrucijada de oportunidades que solo pueden cobrar pleno sentido o "re-significarse", según decía- 
mos, si la intervención educativa en medio de un laberinto así se parece al "hilo de Ariadna" del mito de Teseo, pues eso es lo que hace el educador o educadora en su trabajo docente, crear conexiones y, a menudo, "rescatar" $u$ orientar a personas que son auténticos "náufragos de la alfabetización". La multialfabetización, la alfabetización académica y, a fin de cuentas, la alfabetización ciudadana son las que pueden convertir a estos lectores náufragos en lectores exploradores; la balsa son los textos, igual que el timón, las redes o la vela, todos son en última instancia los artilugios o pertrechos de este lector en construcción, fin supremo a nuestro juicio de la tarea profesional del docente.

\section{ReFERENCIAS BIBLIOGRÁFICAS}

Bajtin, M. (1974). La cultura popular en la Edad Media y Renacimiento. Barcelona: Barral.

Barton, D. y Hamilton, M. (1998). Local literacies: Reading and writing in one community. New York: Routledge.

Bauman, Z. (2002). Modernidad líquida. México: Fondo de Cultura Económica.

Benjamin, W. (1986). El narrador. Consideraciones sobre la obra de Nicolai Leskov. En Sobre el programa de la filosofía futura, pp. 189-212.

Besson, A. (2004). D'Asimov à Tolkien: cycles et séries dans la littérature de genre. París: CNRS.

Bolter, J. D. et al. (2000). Remediation: Understanding new media. Massachusetts: MIT Press.

Butlen, M. (2005). Paradojas de la lectura escolar. Revista de Educación, 1, 139-151.

Calvino, I. (2012). Por qué leer los clásicos. Madrid: Siruela.

Cassany, D. (2006). Tras las líneas: sobre la lectura contemporánea. Barcelona: Anagrama.

Castedo, M. (1995). Construcción de lectores y escritores. Lectura y Vida, 16(3), 2-21.

Cucuzza, H. R. (2011). El Proyecto Histelea: nuevas aperturas teóricas y desafíos metodológicos. Magis: Revista Internacional de Investigación en Educación, 4(7), 45-66.

Chartier, R. (2006). Materialidad del texto, textualidad del libro. Orbis Tertius, 11, 12-19.

Chartier, R. (1992). El mundo como representación: estudios sobre historia cultural. Barcelona: Gedisa.

De San José, L. (1945). Concordancias de las obras y escritos de Santa Teresa Jesús. Burgos: El Monte Carmelo.

Dufays, J. L. (2005). Pour une lecture littéraire: histoire, théories, pistes pour la classe. Bruselas: De Boeck Supérieur.

Escarpit, R. (1958). Sociología de la literatura. Barcelona: Edima.

Fainholc, B. (2004). Lectura crítica en Internet. Análisis y utilización de los recursos tecnológicos en educación. Argentina: Homo Sapiens.

Fischer, H. (2002). El choque digital. Buenos Aires: Editorial de la Universidad Nacional de Tres de Febrero. 
Galina-Russell, I. (2011). ¿Qué son las humanidades digitales? Revista digital universitaria, 12(7), 3-10.

García Berrio, A. (2009). Retórica figural. Esquemas argumentativos en los sonetos de Garcilaso. En El centro en lo múltiple (selección de ensayos) II. El contenido de las formas (pp. 228-240). Barcelona: Anthropos.

Giesecke, M. y García, F. (2009). En busca de ideales educativos postipográficos. Magis: Revista Internacional de Investigación en Educación, 2(3), 29-46.

Iser, W. (1987). El acto de leer: teoría del efecto estético. Madrid: Taurus.

Jenkins, H. (2006). Convergence culture: la cultura de la convergencia de los medios de comunicación. Barcelona: Paidós.

Jockers, M. L. (2013). Macroanalysis. Digital Media and Literary History. Illinois: University of Illinois Press.

Lovink, G. (2013). Zero comments: Blogging and critical Internet culture. London: Routledge.

Manovich, L. (2002). New media from Borges to HTML. The new media reader, 95, 13-28.

Marchant Rivera, A. (1993). Literatura e historia de la cultura escrita: prácticas bibliófilas y escriturarias en "El Quijote" de Cervantes. Málaga: Universidad de Málaga.

Martín-Barbero, J. L. (2006). Recepción de medios y consumo cultural: travesías. En G. Sunkel (Coord.), El Consumo Cultural en América Latina (pp.47-71). Colombia: Convenio Andrés Bello.

Martín-Santos, L. (1975). Tiempo de destrucción. Barcelona: Seix Barral.

Martos García, A. et al. (2015). Etiología y hermenéutica del motivo folclórico y el proverbio clásico" Tesoro de Duendes. Andamios, 11(27), 23-35.

Martos García, A. E. (2009a). Introducción al mundo de las sagas. Badajoz: Universidad de Extremadura.

Martos García, A. E. (2009b). Tecnologías de la palabra en la era digital: de la cultura letrada a la cibercultura. RELATEC: Revista Latinoamericana de Tecnología Educativa, 8(2), 15-37.

Martos García, A. E. (2011). Sobre el concepto de apropiación de Chartier y las nuevas prácticas culturales de lectura (el fan fiction). Álabe, (4).

Martos Núñez, E. (2006). "Tunear" los libros: series, fanfiction, blogs y otras prácticas emergentes de lectura. Ocnos: Revista de estudios sobre lectura, 2, 63-77.

Martos Núñez, E. (2012). La lectura y la escritura en el s. XXI: Cultura letrada y modernidad. Álabe: Revista de Investigación sobre Lectura y Escritura, 5.

Martos Núñez, E. et al. (2014). Textos integrados y narratologías míticas y posmodernas: algunos paralelismos. Revista chilena de literatura, 87, 183-211.

Morant Deusa, I. y Bolufer Peruga, M. (2009). El matrimonio en el corazón de la sociedad: introducción historiográfica. Tiempos modernos: Revista Electrónica de Historia Moderna, 6(18).

Moretti, F. (2005). Graphs, Maps, Trees: Abstract Models for Literary History. London: Verso.

Moretti, F (2007). La literatura vista desde lejos. Barcelona: Marbot. 
Moretti, F (2013). Distant Reading. London: Verso.

Morin, E. (1994). Introducción al pensamiento complejo. Barcelona: Gedisa.

Morin, E. et al. (2002). Educar en la era planetaria: el pensamiento complejo como método de aprendizaje en el error y la incertidumbre humana. Valladolid: Secretariado de Publicaciones e Intercambio Cultural.

Muter, P. et al. (1982). Extended reading of continuous text on television screens. $\mathrm{Hu}$ man Factors, 24, 501-508.

Muter, P. y Maurutto, P. (1991). Reading and skimming from computer screens and books: the paperless office revisited? Behaviour \& Information Technology, 10(4), 257-266.

Oakeshott, M. (2009). La voz del aprendizaje liberal. Madrid: Katz.

Olson, D. (1994). El mundo sobre el papel. Barcelona: Gedisa.

Ong, W. J. (1993). Oralidad y escritura. México: Fondo de Cultura Económica.

Ortiz Ballesteros, A. M. (2005). El derecho de los jóvenes a "no leer" El Quijote. Ocnos: Revista de Estudios sobre Lectura, 1, 61-74.

Peterson, R. (1992). Understanding Audience Segmentation: From Elite and Mass to Omnivore and Univore. Poetics, 21(4), 243-258.

Piscitelli, A. (2011). El Paréntesis de Gutenberg: la religión digital en la era de las pantallas ubicuas. Buenos Aires: Santillana.

Popper, K. (1992). La sociedad abierta y sus enemigos. Barcelona: Planeta-De Agostini.

Prensky, M. (2011). Enseñar a nativos digitales. Madrid: SM.

Rodríguez Reyes, C. (2005). Hipertexto y literatura en Red. El relato digital, los escrilectores y la Cibercultura. Textos de la CiberSociedad, 7.

Sánchez Corral, L. (2005). Violencia, discurso y público infantil. Cuenca: Universidad de Castilla La Mancha.

Sauerberg, L. O. (2009). The encyclopedia and the Gutenberg Parenthesis. Media in Transition, 6(2).

TV Tropes Foundation (2012). TV Tropes [web]. Recuperado de: http://tvtropes.org/. Verdú, V. (2006). El estilo del mundo: la vida en el capitalismo de ficción. Barcelona: Anagrama. 